\title{
IDENTIFIKASI UNSUR PENYUSUN TANAH DESA BABANGE KABUPATEN BANTAENG MENGGUNAKAN METODE $X$-RAY FLUORESCENCE (XRF)
}

\author{
Nurul Namira*, Rahmaniah, Ayusari Wahyuni \\ Jurusan Fisika \\ Fakultas Sains dan Teknologi UIN Alauddin Makassar \\ Jl. Sultan Alauddin No. 63, Gowa, Sulawesi Selatan. 92113 \\ *E-mail: nurulnamira4175@gmail.com
}

\begin{abstract}
Abstrak: Telah dilakukan penelitian dengan tujuan untuk mengetahui unsur penyusun dan jumlah unsur yang terkandung dalam tanah Desa Babange Kabupaten Bantaeng dengan menggunakan metode XRF (X-ray fluorescense). Desa Babange Kabupaten Bantaeng terletak di daerah kaki gunung api Lompobattang yang artinya bisa didapatkan potensi geothermal pada lokasi penelitian. Pengambilan sampel tanah dilakukan pada tiga titik berbeda dengan kedalaman masing-masing $0 \mathrm{~cm}, 60 \mathrm{~cm}$ dan $100 \mathrm{~cm}$. Hasil uji XRF menunjukkan unsur yang terkandung dalam tanah Desa Babange adalah besi $(\mathrm{Fe})$, titanium (Ti), silikon $(\mathrm{Si})$, calcium $(\mathrm{Ca})$, mangan $(\mathrm{Mn})$, zirkonium $(\mathrm{Zr})$, kalium $(\mathrm{K})$, stronsium $(\mathrm{Sr})$, seng $(\mathrm{Zn})$, niobium $(\mathrm{Nb})$, bromin $(\mathrm{Br})$, iodin $(\mathrm{I})$, indium $(\mathrm{In})$, tembaga $(\mathrm{Cu})$, timah $(\mathrm{Sn})$, barium $(\mathrm{Ba})$, galium (Ga) dan nikel (Ni). Unsur dengan kadar tertinggi adalah $\mathrm{Fe}, \mathrm{Ti}, \mathrm{Si}, \mathrm{Ca}$ dan Mn. Unsur Fe dengan kadar tertinggi didapatkan pada titik $\mathrm{C}$ pada kedalaman $100 \mathrm{~cm}$ sebesar $71,72 \%$. Unsur Ti dengan kadar terbesar didapatkan pada titik A pada kedalaman $50 \mathrm{~cm}$ sebesar $6,77 \%$. Unsur Si dengan kadar terbesar didapatkan pada titik A pada kedalaman $100 \mathrm{~cm}$ sebesar 13,01\%. Unsur Ca dengan kadar terbesar didapatkan pada titik A pada kedalaman $0 \mathrm{~cm}$ sebesar 2,87\%, dan unsur Mn dengan kadar terbesar terdapat pada titik $\mathrm{C}$ pada kedalaman $0 \mathrm{~cm}$ sebesar 3,10\%. Berdasarkan besarnya kandungan unsur yang telah diperoleh maka pada lokasi penelitian memiliki potensi geothermal yang rendah meskipun terdapat pada daerah kaki gunung api.
\end{abstract}

Kata Kunci: geothermal, tanah, unsur, X-ray fluorescense

\section{PENDAHULUAN}

I dentifikasi merupakan suatu proses untuk mengetahui kandungan yang terdapat pada suatu objek atau penyusun-penyusunnya. Dengan mengidentifikasi suatu objek dapat mempermudah untuk mengetahui fungsi dan manfaat dari objek yang diidentifikasi. Tanah merupakan salah satu sumber daya alam dengan jumlah yang melimpah. Di dalam tanah juga terdapat banyak mineral-mineral penyusun tanah itu sendiri yang dapat dimanfaatkan dengan cara identifikasi. Tanah terbentuk dari bebatuan yang berada di bawah. Perkembangan ini berlangsung terus menerus dari waktu ke waktu dan berada di bawah pengaruh interaksi lingkungan sekitarnya, baik lingkungan (makhluk hidup) maupun bukan makhluk hidup (terutama iklim). Perkembangan tanah ini mengakibatkan terjadinya perubahan sifat fisik tanah, morfologi tanah, sifat kimia tanah, dan sifat biologi (Gusmara, 2016). 
Sulawesi Selatan merupakan salah satu provinsi yang di dalamnya terdapat berbagai keanekaragaman sumber daya yang sangat bermanfaat seperti sumber daya alam dan sumber daya mineral. Salah satu kabupaten yang diketahui memiliki banyak sumber daya alam yaitu Kabupaten Bantaeng. Berdasarkan Buku Putih Sanitasi Kabupaten Bantaeng diketahui bahwa terdapat enam satuan kelompok karakterisasi batuan dan tanah, yaitu satuan Tufa, satuan Breksi Lahar, satuan Lava Basal, satuan Aglomerat, satuan Intrusi Andesit dan endapan alluvial. Adapun jenis tanah Kabupaten Bantaeng yaitu jenis Andosol cokelat, Latosal cokelat kuning, Mediteran, dan Regosol cokelat kelabu (Pemerintah Kabupaten Bantaeng, 2013). Desa Babange merupakan daerah atau kawasan yang berada di sekitar kaki gunung Lompobattang sehingga memungkinkan untuk didapatkan potensi geothermal di daerah tersebut.

Hipotesa awal penelitian didasarkan pada penelitian yang telah dilakukan oleh Rahmaniah \& Wahyuni (2020) dengan judul penelitan Survey on potential of geothermal in Lompobattang Mountains South Sulawesi by resistivity method dengan hasil penelitian yang menyatakan bahwa berdasarkan peta geologi daerah penelitian terdapat batuan lava, breksi, konglomerat, endapan lava dan tufa yang juga menunjukkan gambaran yang hampir sama dengan hasil interpretasi metode geolistrik resistivitas. Meskipun penemuan batuan penyusun berupa breksi kadang juga ditemukan pada formasi batuan vulkanik di wilayah Gorontalo, namun belum dapat disimpulkan potensi panas bumi tersebut Oleh karena itu perlu diketahui kandungan-kandungan unsur yang terdapat pada lokasi penelitian, salah satunya dengan menggunakan metode XRF. Unsur kimia adalah sebuah zat yang hanya mengandung satu jenis atom yang tidak bisa diuraikan menjadi lebih sederhana lagi baik secara fisika maupun secara kimia. Bagian terkecil dari unsur disebut dengan atom, yang tidak dapat bergabung maupun bisa bergabung membentuk molekul atau struktur yang lebih besar. Unsur dikelompokkan menjadi tiga bagian yaitu logam, non logam dan metalloid (Harwanto et al., 2019).

Mineral yang terkandung dalam tanah dapat berperan cukup potensial bagi tanah, karena di dalam beberapa mineral dari batuan terkandung unsur-unsur penting yang dapat digunakan untuk mempertahankan dan menambah produktivitas lahan maupun hasil pertanian (Bali et al., 2018). Mineral adalah senyawa anorganik dengan berbagai sifat fisik dan kimia yang digolongkan menjadi mineral primer dan sekunder. Mineral-mineral primer mengalami pelapukan dan melepaskan sejumlah elemen-elemen ke dalam larutan tanah. Beberapa elemen-elemen yang dilepaskan dalam proses pelapukan akan membentuk ikatan dengan elemen lainnya membentuk mineral-mineral sekunder. Mineral sekunder yang dihasilkan dalam proses pelapukan umumnya memiliki ukuran partikel yang kecil. Oleh karena itu mineral sekunder umumnya mendominasi fraksi liat tanah (Mustafa et al., 2012).

\section{METODE PENELITIAN}

Metode yang digunakan pada penelitian kali ini yaitu metode XRF ( $X$-ray fluorescence) yang merupakan salah satu cara untuk dapat mengidentifikasi suatu objek material seperti tanah. X-ray fluorescence (XRF) spektrometer adalah alat uji yang digunakan untuk menganalisis unsur yang terkandung dalam bahan secara kualitatif maupun kuantitatif. Analisis kualitatif memberikan informasi jenis unsur yang terkandung dalam bahan yang dianalisis, yang ditunjukkan oleh adanya spektrum unsur pada energi sinar-x. sedangkan analisis kuantitatif memberikan informasi jumlah unsur yang terkandung dalam bahan yang ditunjukkan oleh ketinggian puncak spektrum (Jamaludin \& Adiantoro, 2012). 
XRF pada umumnya digunakan untuk menentukan unsur-unsur penyusun suatu material. Metode ini banyak digunakan karena selain dengan penggunaannya yang mudah, juga biaya yang digunakan untuk metode ini relatif murah. Selain itu proses analisa metode XRF juga cepat dan hanya membutuhkan sedikit sampel. Oleh karena itu dengan menggunakan metode ini maka akan lebih mempermudah proses identifikasi suatu objek dengan mendapatkan hasil yang akurat. Adapun cara pengambilan sampel dilakukan pada tiga titik berbeda dengan masing-masing titik dilakukan tiga kali penggalian masing-masing pada kedalaman $0 \mathrm{~cm}, 50 \mathrm{~cm}$ dan $100 \mathrm{~cm}$.

\section{HASIL DAN PEMBAHASAN}

Lokasi penelitian ini terletak di Desa Babange Kecamatan Eremerasa Kabupaten Bantaeng. Peta lokasi penelitian ditunjukkan pada Gambar 1.

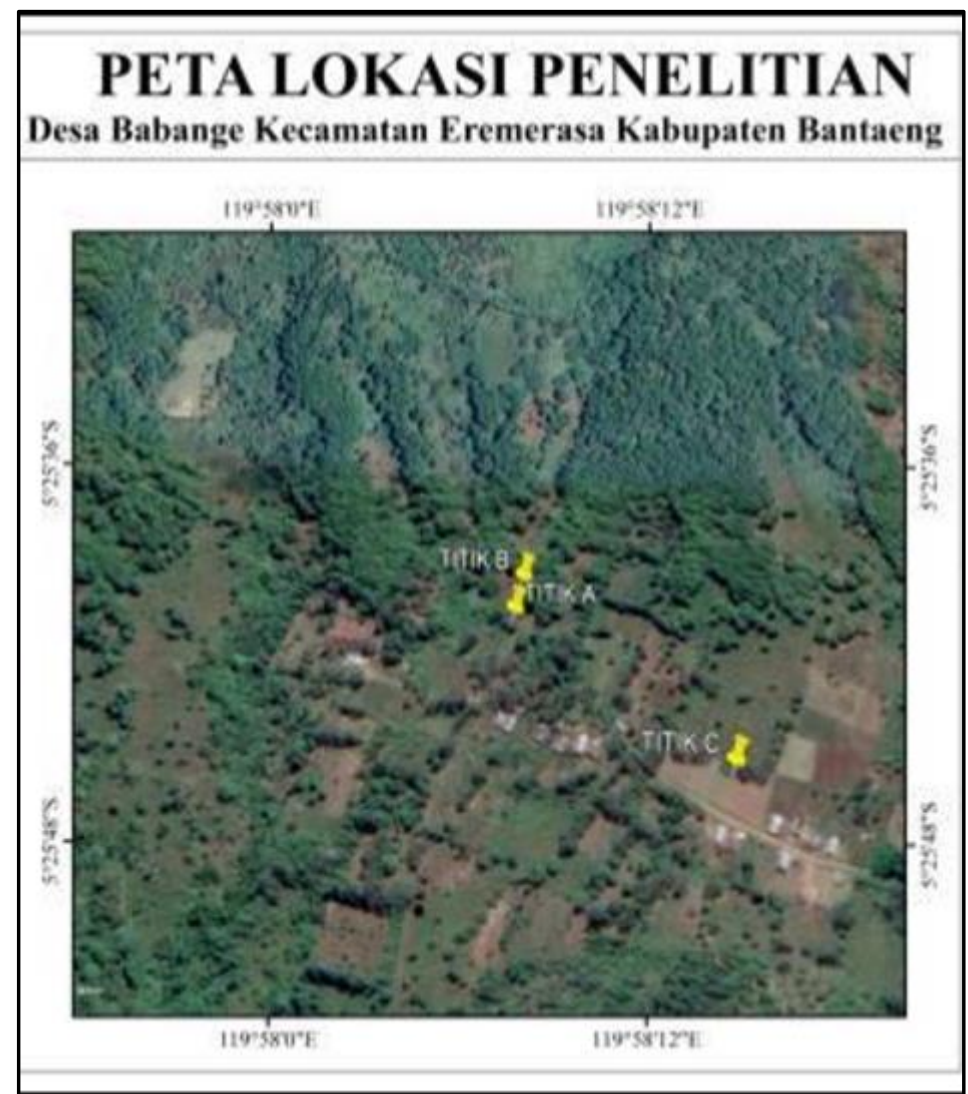

Gambar 1. Peta lokasi penelitian

Terdapat bermacam-macam jenis unsur yang terkandung dalam tanah Desa Babange Kabupaten Bantaeng. Jenis unsur dengan kadar tertinggi yaitu Fe, Ti, Si, Ca, dan Mn. Besarnya kadar unsur berbeda setiap titiknya, perbandingan kadar unsur tersebut dapat dilihat pada Gambar 2, Gambar 3 dan Gambar 4 yang menunjukkan perbandingan unsur pada setiap kedalaman. 


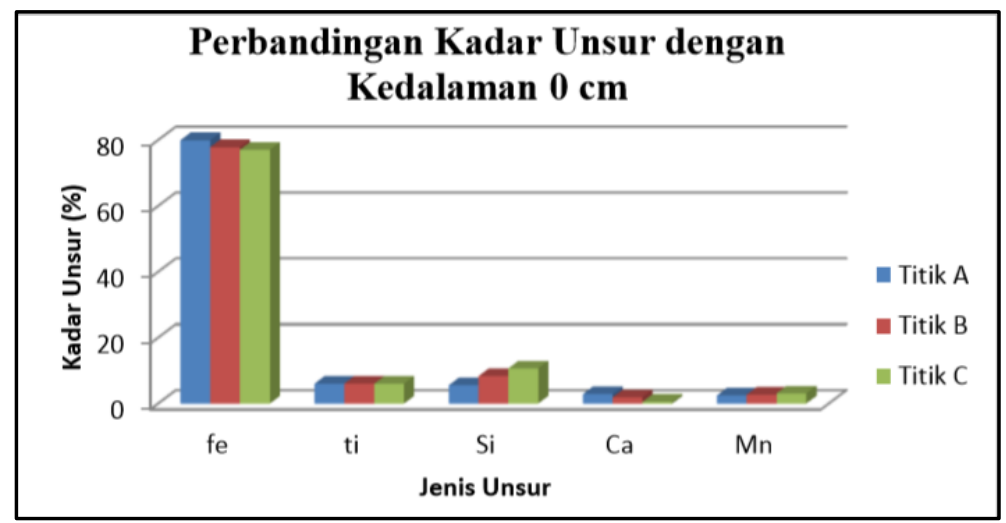

Gambar 2. Persentase perbandingan kadar unsur pada kedalaman $0 \mathrm{~cm}$

Gambar 2 merupakan hasil uji laboratorium dari tiga titik berbeda dengan kedalaman $0 \mathrm{~cm}$. Pada grafik tersebut menunjukkan bahwa besarnya kadar unsur dari beberapa jenis unsur yang didapatkan berbeda-beda. Unsur Fe dengan kandungan tertinggi didapatkan di titik pertama jika dibandingkan dengan dua titik yang lainnya yaitu sebesar 79,98\%. Hal ini dikarenakan faktor lingkungan, yang mana pada titik pertama berlokasi di sekitar perkebunan warga yang di dalamnya terdapat banyak tanaman yang hampir semuanya diberi pupuk. Unsur Ti pada masing-masing titik secara berurutan besarnya hampir sama yaitu $6,07 \% ; 6,11 \%$ dan $6,06 \%$. Unsur Si dengan kadar terbesar pada tiga titik pengambilan sampel yaitu pada titik $\mathrm{C}$ sebesar $10,71 \%$. Unsur Ca dengan kandungan terbesar didapatkan pada titik A yaitu sebesar 2,87\%, dan unsur Mn dengan kandungan terbesar didapatkan pada titik $\mathrm{C}$ yaitu sebesar 3,10\%.

Besarnya unsur Fe yang terdapat pada lokasi penelitian dapat dipengaruhi oleh pelapukan batuan-batuan di sekitarnya. Batuan yang dimaksud adalah batuan sedimen yang mana batuan sedimen merupakan batuan yang mengandung lebih banyak zat besi dan dari pelapukan batuan sedimen tersebut mengasilkan jenis tanah mediteran. Selain itu, besarnya unsur Fe juga dipengaruhi oleh topografi yang mana secara teoritis daerah yang baik untuk tempat pengendapan bijih logam adalah punggung bukit yang landai dimana pada tempat ini pelapukan secara mekanis dan kimia memungkinkan terbentuknya endapan bijih logam pada batuan ultrabasa (Alam, 2011)

Lokasi pengambilan sampel pada titik $\mathrm{C}$ merupakan lokasi yang paling sedikit terdapat pohon-pohon maupun tumbuhan tinggi dan besar sehingga tidak menutup kemungkinan banyak hal lain yang dapat mengakibatkan tingginya unsur Si yang didapatkan pada lokasi ini. Hal ini telah dijelaskan oleh Freiburghaus et al. (1998) bahwa silikon paling banyak terdistribusi pada debu, pasir, planetoid dalam berbagai aspek seperti silikon dioksida maupun silika.

Gambar 2 menunjukkan bahwa unsur Fe adalah unsur dengan kadar tertinggi. Pada pengambilan sampel dengan kedalaman $50 \mathrm{~cm}$ juga didapatkan hasil bahwa unsur $\mathrm{Fe}$ adalah unsur tertinggi yang ditemukan, dengan kadar tertinggi yaitu pada titik A sebesar $82,79 \%$ (Gambar 3). Unsur Ti dengan kadar tertinggi juga terdapat pada titik A sebesar $6,77 \%$, unsur Si dengan kadar tertinggi terdapat pada titik $\mathrm{C}$ dengan besar kandungan unsur $12,81 \%$. Unsur Ca pada hasil uji laboratorium hanya didapatkan pada dua titik yaitu titik A dan titik B sedangkan titik $\mathrm{C}$ pada kedalaman $50 \mathrm{~cm}$ tidak didapatkan kandungan unsur dengan jenis $\mathrm{Ca}$, besar kandungan unsur $\mathrm{Ca}$ pada titik $\mathrm{A}$ dan $\mathrm{B}$ masing-masing $0,751 \%$ dan $1,04 \%$ sehingga diketahui bahwa unsur $\mathrm{Ca}$ dengan kandungan terbesar berada pada titik B. Unsur Mn dengan kadar tertinggi terdapat pada titik B yaitu sebesar $2,53 \%$. 
Pada kedalaman $50 \mathrm{~cm}$, unsur Ca tidak ditemukan pada titik C. Hal ini bisa saja disebabkan karena tidak terbaca oleh alat uji karena jumlahnya terlalu kecil sehingga alat tidak mendeteksi adanya unsur $\mathrm{Ca}$ pada titik $\mathrm{C}$ pada kedalaman $50 \mathrm{~cm}$ ini. Akan tetapi didapatkan unsur Ca pada titik A dan titik B. Unsur Ca yang didapatkan pada lokasi penelitian disebabkan karena adanya endapan abu vulkanik yang mana abu vulkanik memiliki komposisi unsur tertinggi yaitu $\mathrm{Ca}, \mathrm{Na}, \mathrm{K}$, dan $\mathrm{Mg}$. Seperti halnya dengan unsur Mn yang didapatkan pada titik A, titik B dan titik $\mathrm{C}$ juga disebabkan oleh endapan abu vulkanik karena pada komposisi abu vulkanik memiliki unsur mikro seperti Fe, Mn, Zn, Cu dan Ti (Cas \& Wright, 1987).

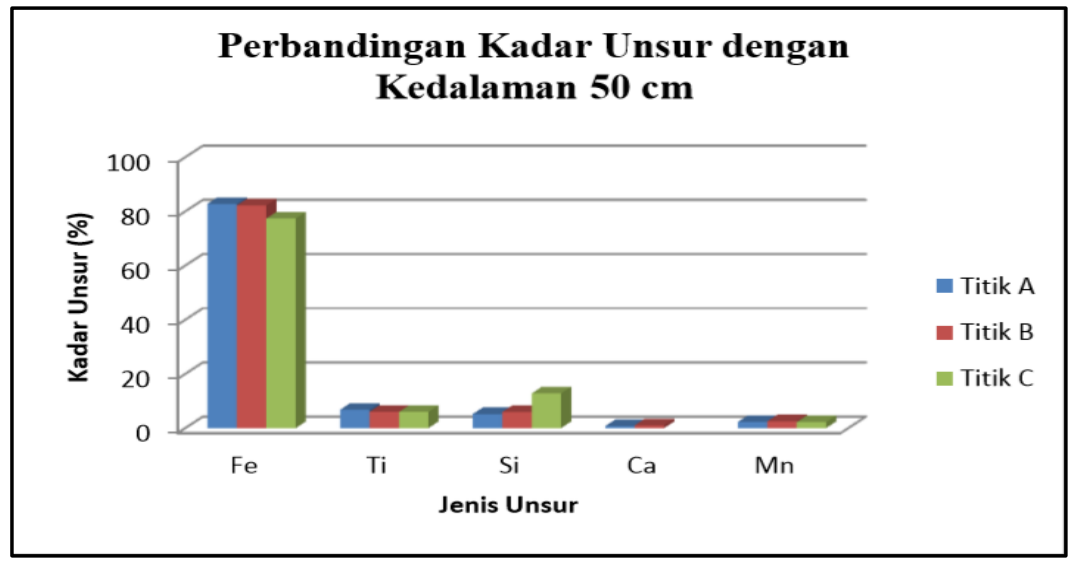

Gambar 3. Persentase perbandingan kadar unsur pada kedalaman $50 \mathrm{~cm}$

Grafik perbandingan jumlah kadar unsur pada kedalaman $100 \mathrm{~cm}$ menunjukkan bahwa unsur Fe dengan kadar tertinggi terdapat pada titik $\mathrm{C}$ yaitu sebesar $83,40 \%$ dan kadar terendah pada titik A sebesar 71,72\% (Gambar 4). Berbeda dengan unsur Fe, unsur Ti dengan kadar tertinggi terdapat pada titik A yaitu sebesar 6,05\% dan kadar terendah terdapat pada titik B sebesar 5,21\%. Unsur Si juga didapatkan hasil yaitu persentase terbesar terdapat pada titik A sebesar 13,02\% dan kadar terendah terdapat pada titik B sebesar 5,21\%. Selanjutnya, unsur Ca dengan kadar tertinggi juga terdapat pada titik A yaitu sebesar $2,31 \%$ dan kadar terendah terdapat pada titik $C$ yaitu sebesar $0,147 \%$. Sedangkan unsur Mn didapatkan hasil bahwa unsur Mn dengan kadar tertinggi terdapat pada titik B sebesar 2,52\% dan kadar terendah terdapat pada titik A sebesar 1,92\%.

Dengan mengetahui kandungan unsur dalam tanah yang terdapat pada Desa Babange Kabupaten Bantaeng ini, maka dapat disimpulkan bahwa untuk potensi geothermal yang bisa didapatkan pada lokasi penelitian ini dapat dikatakan masih kurang. Hal ini disebabkan karena unsur pendukung potensi geothermal pada lokasi penelitian ini tidak memadai. Unsur-unsur yang dimaksud yaitu Si dan Ca. Unsur Si pada lokasi penelitian ini dengan persentase tertinggi hanya didapatkan sebesar 13,02\% sedangkan pengaruh silika terhadap potensi geothermal sangat penting karena kandungan silika yang tinggi dapat menandakan bahwa material (tanah) tersebut langsung berasal dari pelapukan batuan pada reservoir (Elder, 1981). Berdasarkan teori, silika tersusun atas silikon dan oksigen dengan sifat konduktor yang sedikit menghantarkan listrik dan besi merupakan logam transisi dengan sifat konduktor yang layak untuk listrik dan panas (Fitriani, 2017). Sedangkan unsur Ca dengan persentase tertinggi hanya didapatkan sebesar 2,87\%.

Beberapa penelitian sebelumnya menunjukkan bahwa besarnya unsur pendukung potensi geothermal sangat berpengaruh terhadap potensi geothermal seperti pada penelitian yang telah dilakukan oleh Fitriani (2017) yang mendapatkan hasil penelitian 
berupa unsur Si sebesar 43,66\% dan unsur Ca sebesar 16,63\% sehingga dapat dipastikan bahwa hasil penelitian yang telah dilakukan menunjukkan bahwa terdapat potensi geothermal pada lokasi penelitian tersebut.

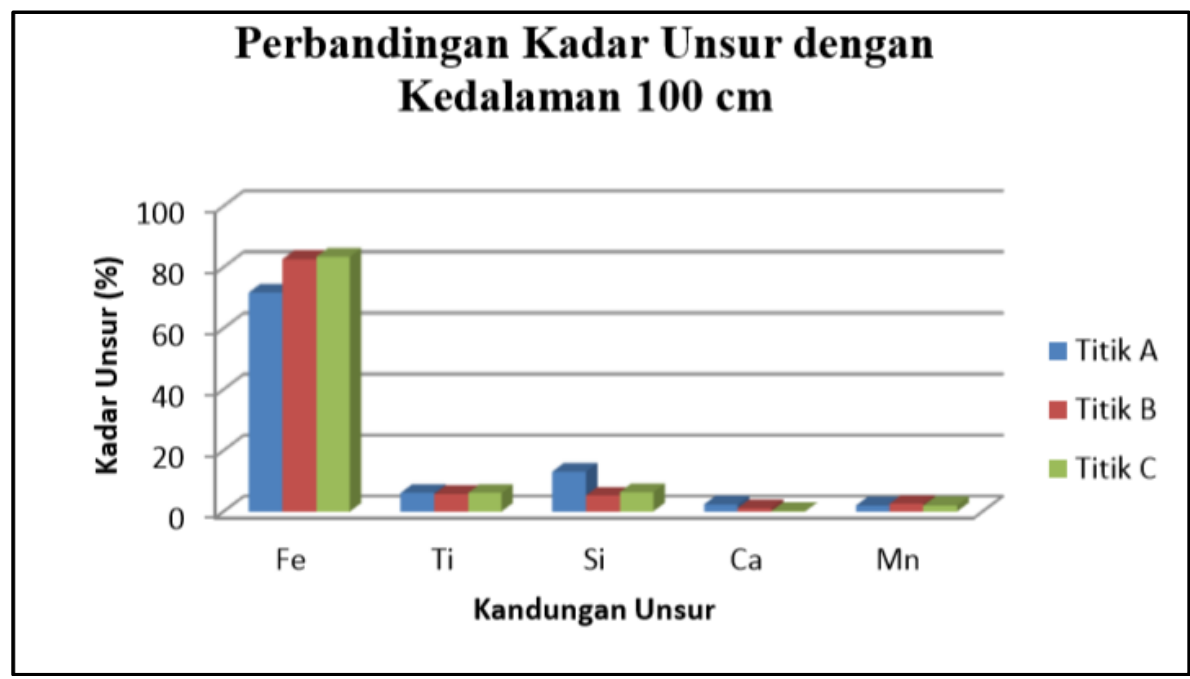

Gambar 4. Persentase perbandingan kadar unsur pada kedalaman $100 \mathrm{~cm}$

\section{KESIMPULAN}

Berdasarkan hasil penelitian dan pembahasan diperoleh kesimpulan yaitu unsur yang menjadi penyusun tanah di Desa Babange Kecamatan Eremerasa Kabupaten Bantaeng yaitu unsur Fe, Si, Ti, K, Ca, Mn, Sr, Zr, Zn, Nb, Br, I, In, Cu, Sn, Ba, Ga, dan Ni. Hasil pengujian XRF menunjukkan besar kandungan unsur yang terkandung dalam batuan di Desa Babange Kecamatan Eremerasa Kabupaten Bantaeng dengan 3 titik pengambilan sampel yang berbeda dengan kedalaman $0 \mathrm{~cm}, 50 \mathrm{~cm}$, dan $100 \mathrm{~cm}$. Unsur Fe dengan kadar tertinggi terdapat pada titik $C$ pada kedalaman $100 \mathrm{~cm}$ sebesar $83,40 \%$. Unsur Ti dengan kadar terbesar terdapat pada titik A pada kedalaman $50 \mathrm{~cm}$ sebesar $6,77 \%$. Unsur Si dengan kadar tertinggi terdapat pada titik A pada kedalaman $100 \mathrm{~cm}$ sebesar 13,02. Unsur Ca dengan kadar tertinggi terdapat pada titik A pada kedalaman 0 $\mathrm{cm}$ sebesar 2,87\%. Unsur Mn dengan kadar tertinggi terdapat pada titik $\mathrm{C}$ pada kedalaman $0 \mathrm{~cm}$ yaitu sebesar $3,10 \%$.

\section{DAFTAR PUSTAKA}

Alam, A.I. (2011). Analisis Perubahan Kadar Nikel Saprolit Dari Kegiatan Eksplorasi Sampai Kegiatan Penambangan Pada PT Gane Permai Sentosa (GPS) Kecamatan Obi Utara Kabupaten Halmahera Selatan Propinsi Maluku Utara. [Skripsi].

Bali, I., A. Ahmad., \& C. Lopulisa. (2018) Identifikasi mineral pembawa hara untuk menilai potensi kesuburan tanah. Ecosolum: Journal of Soil Science and Environmental, 7(2), 81-100. https://doi.org/10.20956/ecosolum.v7i2.6880.

Cas, R.A.F., \& J.V. Wright. (1988). Volcanic Successions Modern and Ancient: A geological Approach to Processes, Products And Successions. London: Chapman \& Hall.

Elder, J. (1981)Geothermal systems. Geothermal systems, 1-2. Doi: 10.1016/0377-0273(82)90075-0.

Fitriani. (2017) Identifikasi Kandungan Mineral Sumber Air Panas di Desa Watu Toa Kecamatan Marioriwawo. [Skripsi]. Makassar: Fakultas Sains dan Teknologi Universitas Islam Negeri Alauddin Makassar.

Gusmara, H. (2016). Bahan Ajar Dasar-Dasar Ilmu Tanah ITN-100. Bengkulu: Universitas Bengkulu.

Harwanto, D., S.R.U.A. Sompie., \& V. Tulenan. (2019). Aplikasi game edukasi pengenalan unsur dan senyawa kimia. Jurnal Teknik Informatika, 14(1), 63-70. https://doi.org/10.35793/jti.14.1. 2019.23838. 
Jamaludin, A., \& D. Adiantoro. (2012). Analisis kerusakan X-ray fluoresence (XRF). PIN: Pengelolaan Instalasi Nuklir, 9-10, 19-28.

Mustafa, M., A. Ahmad., M. Ansar., \& M. Syafiuddin. (2012) Dasar-Dasar Ilmu Tanah. Makassar: Univesitas Hasanuddin.

Rahmaniah., \& A. Wahyuni. (2020). Survey on potential of geothermal in Lompobattang Mountains South Sulawesi by resistivity method. IOP Conference Series: Earth and Environmental Science, 575(1), 2-6. Doi: 10.1088/1755-1315/575/1/012160.

Thielemann, F.K., T. Rauscher., C. Freiburghaus., K. Nomoto., M. Hashimoto., B. Pfeiffer., K.-L. Kratz. (1998). Nucleosynthesis Basics and Applications to Supernovae. Cambridge: Cambridge University Press. 